\title{
Interferência do ácido ascórbico na dosagem glicêmica
}

Aline Cardoso Barbosa' Tania Cristina Andrade ${ }^{2}$

\section{Resumo}

Sabe-se que exames laboratoriais estão sujeitos a fatores interferentes. A literatura científica cita interferência do ácido ascórbico em dosagens que envolvam oxirredução, como a glicêmica. Devido a isto, buscou-se avaliar o efeito do ácido ascórbico sobre a dosagem glicêmica em dois tipos de soro controle submetidos a diferentes concentrações de ácido ascórbico, variando de 2,5 a 100 $\mathrm{mg} / \mathrm{dL}$. Utilizou-se um soro controle com valores normais de glicemia e outro com valores patológicos. Observou-se uma diminuição significativa $(\mathrm{p}<0,01) \mathrm{da}$ glicemia em ambos, porém a amostra normal apresentou maior correlação negativa, chegando a 74\% com a concentração de $100 \mathrm{mg} / \mathrm{dL}$ de ácido ascórbico, enquanto na amostra correspondente do soro patológico houve uma redução de $40 \%$ na dosagem glicêmica. O presente estudo demonstrou haver uma correlação negativa entre concentrações crescentes de ácido ascórbico e dosagem glicêmica.

Palavras-chave: Glicemia. Ácido ascórbico. Vitamina C.

\section{Introdução}

Segundo a OMS (Organização Mundial de Saúde), atualmente $180 \mathrm{mi}-$ lhões de pessoas no mundo apresentam Diabetes Mellitus (DM), das quais 3 milhões vêm a óbito por ano devido à doença. Estima-se que estes números dupliquem até o ano de 2030. Em 2005, a população de diabéticos no Brasil era superior a 4,5 milhões de pessoas, fato que colocou o país entre aqueles com o maior número de diabéticos do mundo (WILL et al., 2004; ROGLIC et al., 2005; WHO, 2008).

\footnotetext{
${ }^{1}$ Estudante de Biomedicina do Centro Universitário de Brasília - UniCEUB.

${ }^{2}$ Mestre Ciências Biológicas, Professora do Centro Universitário de Brasília - UniCEUB.
} 
A DM é uma condição definida pela hiperglicemia, associada à redução da expectativa de vida. Logo, para uma maior sobrevida e melhor qualidade de vida do paciente, é necessário o controle constante dos índices de glicose (SKYLER, 2004; IDF, 2006; BERTONI, 2008).

Essa avaliação é fundamental para o paciente visto que lhe fornece o diagnóstico, melhora seu acompanhamento e avalia o tratamento, além de medir precisamente os níveis de glicose e avaliar possíveis desordens do metabolismo de carboidratos. Por isso, a dosagem glicêmica é hoje um dos mais importantes parâmetros laboratoriais (HEISE et al., 2004).

No entanto, as rotinas laboratoriais estão sujeitas a sofrer diversas interferências. Especificamente para a dosagem glicêmica, os fatores interferentes incluem exercícios físicos, estresse e o ácido ascórbico que, se presente em amostras biológicas pode interferir em técnicas que utilizem reações de oxirredução (FORNARO, 1998; VIEIRA, 2002; MARTINELLO et al., 2003).

O ácido ascórbico é hidrossolúvel, redutor relativamente forte, possui forma de cristal branco e não é utilizado para fins estruturais nem geração de energia, sendo que os seres humanos não apresentam a enzima responsável pela síntese própria do ácido ascórbico, obtendo-o unicamente através da alimentação (SMIRNOFF, 2000; AZULAY et al., 2003). Superdoses podem interferir em testes laboratoriais para glicose e oxalato de cálcio na urina e para níveis de hemoglobina no sangue (BURTIS et al., 1996; FUCHS et al., 1998; BENDER, 1999). Estas interferências têm valor importante nas análises clínicas porque podem modificar o diagnóstico clínico-laboratorial, gerando falsos resultados, que devem ser evitados (MARTINELLO et al., 2003).

No Brasil, poucas pesquisas avaliaram a interferência negativa do ácido ascórbico em dosagens séricas, sendo maior o enfoque para a interferência na avaliação de glicosúria. Assim, os objetivos do presente estudo foram examinar o efeito do ácido ascórbico sobre as dosagens de glicemia, buscando determinar as concentrações aproximadas de vitamina $\mathrm{C}$ que geram interferência nos exames e relacioná-las com o cotidiano laboratorial, a fim de evitar falsos diagnósticos. 


\section{Materiais e métodos}

Para a realização do presente trabalho, foi dissolvido um comprimido de ácido ascórbico de $500 \mathrm{mg}$ em $50 \mathrm{~mL}$ de água, filtrado e adicionado à $4 \mathrm{~mL}$ de soro controle com concentração de glicose conhecida, formando assim, uma solução estoque de Soro com concentração final de $200 \mathrm{mg} / \mathrm{dL}$ de ácido ascórbico. Dessa solução foram retiradas alíquotas e estas foram diluídas, a fim de formar novas soluções com concentrações determinadas, distintas e crescentes de ácido ascórbico, tais como 2.5, 5, 10, 50 e 100mg/dL. Foram realizadas duas baterias desse experimento, onde na primeira utilizaram-se o soro normal e na segunda, soro patológico, ambos comercializados pela Doles ${ }^{\circledR}$.

As determinações das glicemias foram feitas em triplicata utilizando a técnica GLUCOX 500, do kit Doles ${ }^{\curvearrowleft}$. A metodologia foi utilizada por ser uma técnica eficaz, rápida e de baixo custo, envolvendo reações de oxirredução, que a literatura descreve como passível de falsos resultados na presença do ácido ascórbico.

Utilizando a média aritmética dos diferentes valores obtidos, estes foram verificados e comparados pela análise de correlação do teste de Wilcox, pelo programa Prisma, onde foi considerado um nível de significância de 5\% $(\mathrm{p}<0,05)$. Foram feitas análises separadas para os valores da bateria com soro controle normal e com soro patológico.

\section{Resultados}

Para analisar a interferência do ácido ascórbico, foram feitas dosagens glicêmicas de amostras de soro controle normal e patológico contendo concentrações finais de 2.5, 5, 10, 50 e 100 mg/dL desta vitamina. A verificação em diferentes concentrações teve por finalidade pesquisar qual o grau de interferência em relação aos níveis basais de ácido ascórbico, considerados entre 0,3 a $2 \mathrm{mg} / \mathrm{dL}$ no sangue de pacientes sem ingestão de suplementos de vitamina C.

A Tabela 1 mostra a média aritmética dos valores da glicemia encontrados após as dosagens com diferentes concentrações de ácido ascórbico nas amostras, onde $0 \mathrm{mg} / \mathrm{dL}$ corresponde à amostra de soro sem a adição de ácido ascórbico. Esta equivale ao controle da bateria e valor de referência para a análise estatística. 
Os valores de referência para o soro controle normal encontra-se entre o intervalo de 77 a $101 \mathrm{mg} / \mathrm{dL}$ enquanto para o soro controle patológico, está compreendido entre 254 e $330 \mathrm{mg} / \mathrm{dL}$. Ambos os intervalos são fornecidos pelo fabricante do kit (Doles $\left.{ }^{\varpi}\right)$. Considerou-se que a dosagem sofreu interferência quando os valores medidos saíram deste intervalo aceitável.

Pode-se observar ainda que os índices glicêmicos diminuíram significativamente após a adição de $\geq 10 \mathrm{mg} / \mathrm{dL}$ de ácido ascórbico no soro controle normal enquanto no soro patológico os níveis significativos de inibição foram aqueles somente acima de $50 \mathrm{mg} / \mathrm{dL}$ de ácido ascórbico.

Para análise da interferência negativa, os valores medidos de glicose no soro controle normal $(88 \mathrm{mg} / \mathrm{dL})$ e no soro controle patológico $(330 \mathrm{mg} / \mathrm{dL})$ foram utilizados como controle e considerados $100 \%$ para o cálculo percentual da interferência negativa gerada pelo ácido ascórbico nas demais amostras, onde houve adição de ácido ascórbico.

Após análise dos parâmetros obtidos do soro patológico com a adição de ácido ascórbico, foram observadas interferências significativas nas determinações de glicose, porém em menor escala quando comparadas às do soro controle normal, também mostrado na Tabela 1. Pode-se observar no Gráfico 1 que há uma relação inversamente proporcional: à medida em que a dose de ácido ascórbico aumenta, a glicemia tem seus níveis diminuídos.

Tabela 1 - Níveis da glicemia e Interferência negativa do ácido ascórbico sobre a dosagem glicêmica

\begin{tabular}{cccccc}
\cline { 2 - 5 } & \multicolumn{2}{c}{ GLICEMIA $(\mathbf{m g} / \mathbf{d L})$} & \multicolumn{2}{c}{ INTERFERENCIA NEGATIVA } \\
\hline $\begin{array}{c}\text { Ácido } \\
\text { Ascórbico } \\
(\mathbf{m g} / \mathbf{d L})\end{array}$ & $\begin{array}{c}\text { Soro Controle } \\
\text { Normal }\end{array}$ & $\begin{array}{c}\text { Soro Controle } \\
\text { Patológico }\end{array}$ & $\begin{array}{c}\text { Soro Controle } \\
\text { Normal }\end{array}$ & $\begin{array}{c}\text { Soro Controle } \\
\text { Patológico }\end{array}$ \\
\hline 100 & 23 & 198 & $74 \%$ & $40 \%$ \\
50 & 42 & 259 & $52 \%$ & $22 \%$ \\
10 & 67 & 302 & $24 \%$ & $8 \%$ \\
5 & 87 & 306 & $2 \%$ & $7 \%$ \\
2,5 & 87 & 318 & $2 \%$ & $3 \%$ \\
0 & 88 & 330 & $0 \%$ & $0 \%$ \\
\hline
\end{tabular}


Os maiores índices de interferência estão justamente nas amostras com maior concentração de vitamina C: acima de $10 \mathrm{mg} / \mathrm{dL}$ para o soro normal e acima de $50 \mathrm{mg} / \mathrm{dL}$ para o soro patológico. Gráfico 1 - Interferência do ácido ascórbico em dosagem glicêmica de soro controle normal e
patológico *p=0,01

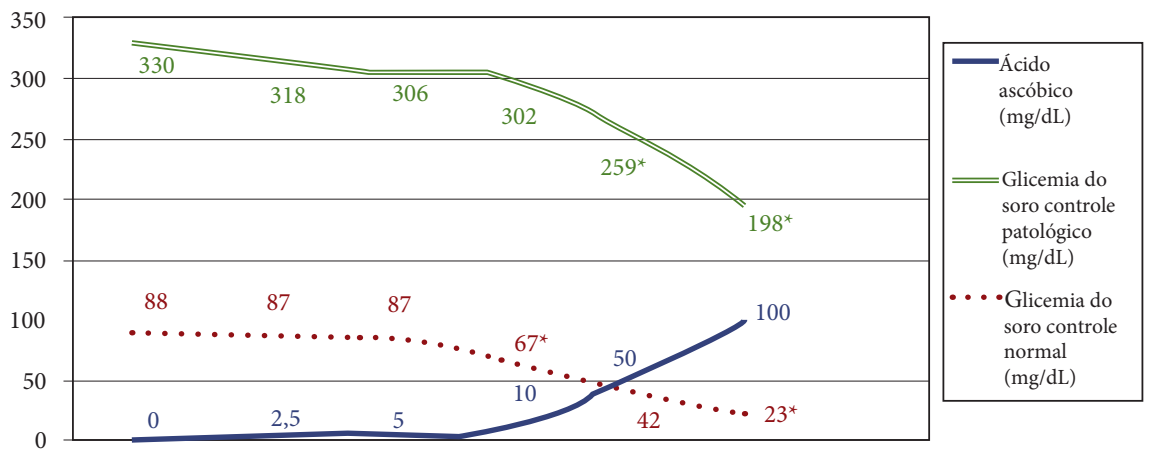

\section{Discussão}

O ácido ascórbico tem sido comumente utilizado para diversos fins terapêuticos, porém, alguns fatores como a gestação, fumo, drogas de abuso, uso de anticoncepcionais orais, além do stress, diminuem seus níveis no sangue (McLEROY et al., 1973; SCHECTMAN et al., 1989; MÁRQUEZ et al., 2001; RONSEIN et al., 2004; HASSAN et al., 2006), por isso é necessário reposição dessa vitamina nesses pacientes.

Além de aumentar a imunidade, combater radicais livres, prevenir contra o escorbuto e melhorar a cicatrização, estudos como o de Kamiji e Oliveira (2005) e o de Cursino et al. (2005) mostram que o ácido ascórbico tem sido estudado como complementação aliada ao tratamento convencional para úlcera e gastrite, assim como contra Pseudomonas aeruginosa. Neste último caso, observa-se um excelente resultado sinérgico aos antibióticos utilizados no tratamento.

De acordo com Cormik e Greene (1996), os índices normais de ácido ascórbico no sangue variam de 0,3 a aproximadamente $2 \mathrm{mg} / \mathrm{dL}$ em pacientes que não ingerem medicação com vitamina C. Martinello e Silva (2003) afirmam que 
em pacientes que estão sujeitos a esses tratamentos, os níveis no plasma sobem para até $4 \mathrm{mg} / \mathrm{dL}$ após a ingestão oral de 4 gramas de ácido ascórbico e em casos de megadoses pode chegar até 40mg/dL. Apesar dos relatos na literatura, o presente trabalho adotou doses ainda maiores que as encontradas após tratamentos com o fim de estudar quantitativamente a interferência citada.

Martinello e Silva (2003) descrevem ainda que megadoses de ácido ascórbico podem causar interferência não apenas na dosagem de glicose, como nas de ácido úrico e triglicerídeos principalmente. Os resultados dos exames para ácido úrico chegam a apresentar resultados 17,8\% abaixo do real devido à interferência negativa gerada. Quanto à glicose, descrevem que a interferência chega a $20 \%$ em casos de megadoses de $10 \mathrm{mg} / \mathrm{dL}$ de ácido ascórbico no plasma e a 5\% em concentrações basais, com ácido ascórbico em $2 \mathrm{mg} / \mathrm{dL}$.

O presente estudo confirma essa influência negativa, com concordância estatística sobre a porcentagem de interferência, visto que a análise de dados demonstrou que, para concentração basal de $10 \mathrm{mg} / \mathrm{dL}$ de ácido ascórbico, houve redução de $24 \%$ na aferição da glicemia enquanto que para a concentração de 2,5 $\mathrm{mg} / \mathrm{dL}$ houve redução de $2 \%$.

Os dados evidenciam uma clara interferência do ácido ascórbico, inversamente proporcional à glicemia aferida. $\mathrm{O}$ que significa que, quanto maior a concentração de ácido ascórbico na amostra, menor o resultado para a dosagem glicêmica. Analisando-os separadamente, observa-se uma grande baixa nos níveis de glicose nas concentrações de ácido ascórbico de 10, 50 e $100 \mathrm{mg} / \mathrm{dL}$, gerando resultados significativos $(\mathrm{p}<0,01)$. No entanto, sabe-se que os níveis basais de ácido ascórbico não chegam a esse valor exceto em situações de megadoses, onde podem alcançar a concentração de $40 \mathrm{mg} / \mathrm{dL}$ de plasma.

Comparando com dados da literatura, é possível observar que a interferência, apesar de existir, provavelmente terá pouca influência na prática laboratorial, visto que a concentração sérica de ácido ascórbico após a ingestão de $4 \mathrm{~g} / \mathrm{dia}$ alcança apenas o valor de $4 \mathrm{mg} / \mathrm{dL}$, distante dos $10 \mathrm{mg} / \mathrm{dL}$ que geram um resultado significativo.

Martinello e Silva (2003) afirmam, ainda, que o ácido ascórbico interfere unicamente na técnica que envolve oxirredução, não existindo uma relação entre 
a quantidade de glicose e ácido ascórbico no plasma. A análise dos valores obtidos da glicemia do soro patológico após a adição de ácido ascórbico mostrou que a interferência negativa ocorreu, porém em menor proporção que no soro normal, onde havia menos glicose no soro. $\mathrm{O}$ fato de a interferência diminuir onde havia maior disponibilidade de glicose confirma o fato descrito pelos autores de que há relação somente na técnica, pois se houvesse entre os elementos, a interferência negativa no soro normal e no patológico deveria estar com proporções invertidas, já que o ácido ascórbico agiria mais onde existisse maior disponibilidade de glicose, o que não aconteceu neste trabalho.

\section{Considerações finais}

Estudos hoje têm mostrado que a enzima ascorbato oxidase tem sido utilizada para anular essa interferência nos exames laboratoriais. Porém, é imprescindível que nos laboratórios haja um cuidado especial dos profissionais envolvidos, além da devida orientação ao paciente sobre o efeito do ácido ascórbico em dosagens laboratoriais, para que este suspenda o uso de vitamina C 72 horas antes da realização dos exames (MARTINELLO et al., 2003). Os resultados do presente e de outros estudos confirmam que o ácido ascórbico exerce uma influência negativa significativa na dosagem glicêmica, em reações de oxirredução, não havendo relação direta entre os níveis de ácido ascórbico e de glicose disponíveis.

\section{Interference of ascorbic acid on glucose dose}

\section{Abstract}

The great majority of clinical exams are subjected to interference factors. The literature mentions an ascorbic acid's interference in exams that involves oxireduction reactions like the glycemic evaluation. The effect of the ascorbic acid on glycemia was evaluated in 2 tipes of control serums subjected to different concentrations of ascorbic acid, ranging from 2,5 to $100 \mathrm{mg} / \mathrm{dL}$. We used a control serum with normal glycemia and a control serum with pathological values. There was a significant glycemia decrease $(\mathrm{p}<0.01)$ in both serum, but the normal sample showed greater negative correlation, up to $74 \%$ with a concentration of $100 \mathrm{mg} /$ 
$\mathrm{dL}$ of ascorbic acid, while in the pathological serum sample a $40 \%$ reduction was observed. Our results showed a negative correlation between crescent ascorbic acid concentrations and glycemic evaluation.

Keywords: Ascorbic acid. Glycemia. Vitamin C.

\section{Referências}

AZULAY, M. M.; LACERDA, C. A. M.; PEREZ, M. A. et al. Vitamina C. Anais Brasileiros de Dermatologia, [S.1.], v. 78, n. 3, p.265-272, 2003.

BERTONI, A. G.; CLARK, J. M.; FEENEY, P. et al. Suboptimal control of glycemia, blood pressure, and LDL cholesterol in overweight adults with diabetes. Journal of Diabetes and its Complications, [S.1.], v. 22, p. 1-9, 2008 .

BURTIS, C. A.; ASHWOOD. E. R. Fundamentos de química clínica. 4. ed. Rio de Janeiro: Guanabara Koogan, 1996.

CORMIK, D. B.; GREENE, H. L. Vitamins: ascorbic acid: tietz textbook of clinical chemistry. 2. ed. Philadelphia: WB Saunders Co, 1999.

CURSINO, L.; SOUZA, E. C.; NASCIMENTO, A. M. A. Synergic interaction between ascorbic acid and antibiotics against Pseudomonas aeruginosa. Brazilian Archives of Biology and Technology, [S.1.], v. 48, n. 3, p. 379-384, 2005.

FORNARO, A.; COICHEV, N. Ácido L-ascórbico: reações de complexação e óxido-redução com alguns íons metálicos de transição. Química Nova, [S.l.], v. 21, n. 5, p.642-650, 1998.

FUCHS, D.; WANNMACHER, L. Farmacologia clínica. 2. ed. Rio de Janeiro: Guanabara Koogan, 1998.

GLEESON, M.; ROBERTSON, J. D.; MAUGHAN, R. J. Influence of exercise on ascorbic acid status in man. Clinical Science, [S.1.], v. 73, p. 501-505, 1987.

HASSAN, G. I.; ONU, A. B. Total serum vitamin C concentration in pregnant women: implications for a healthy pregnancy. Revista Brasileira de Saúde Materno Infantil, [S.l.], v. 6, n. 3, p. 293-296, 2006. 
HEISE, H. M.; ABEL, P. Clinical analysis: glucose. In: WORSFOLD, P. J.; TOWNSHEND, A.; POOLE, C. F. Encyclopedia of analytical science. 2. ed. Oxford: Elsevier, v. 2, p. 152-166, 2004.

HOFFMANN, L.; RICHTER, M. I.; SOARES, M. et al. Vitaminas. Joinville: Instituto Educacional Luterano de Santa Catarina, 2000.

IDF. Definition and diagnosis of diabetes mellitus and intermediate hyperglycemia. Geneva; Switzerland: World Health Organization, 2006.

KAMIJI, M. M.; OLIVEIRA, R. B. Efeito da administração de vitamina C sobre a colonização do estômago por Helicobacter pylori. Arquivos de Gastroenterologia, [S.l.], v. 42, n. 3, p. 167-172, 2005.

MÁRQUEZ, M.; RINCÓN, M.; CARMEN, R. S. N. et al. Niveles séricos de vitamina $\mathrm{C}$ em adultos jóvenes consumidores crônicos de drogas de abuso. Investigación Clínica, [S.l.], v. 42, n. 3, p.183-194, 2001.

MARTINELLO, F.; SILVA, E. L. Interferência do ácido ascórbico nas determinações de parâmetros bioquímicos séricos: estudos in vivo e in vitro. Jornal Brasileiro de Patologia e Medicina Laboratorial, [S.1.], v. 39, n. 4, p. 323-334, 2003.

MCLEROY, V. J.; SCHENDEL, H. E. Influence of oral contraceptives on ascorbic acid concentrations in healthy, sexually mature women. American Journal of Clinical Nutrition, [S.1.], v. 26, p. 191-196, 1973.

OGA, S. Fundamentos de toxicologia. 2. ed. São Paulo: Atheneu, 1996.

ROGLIC, G.; UNWIN, N.; BENNETT, P.H. et al. The burden of mortality attributable to diabetes. Diabetes Care, [S.l.], v. 28, n. 9, p. 2130-2135, 2005.

ROMERO, L. G.; CHARRO, A. L.; CALLE-PASCUAL, A. L. Índice glucémico y tratamiento nutricional de las personas con Diabetes Mellitus. Rev. Endocrinol Nutr., [S.l.], v. 49, n. 7, p. 232-239, 2002.

RONSEIN, G. E.; DUTRA, R. L.; SILVA, E. L. et al. Influência do stress nos níveis sangüíneos de lipídios, ácido ascórbico, zinco e outros parâmetros bioquímicos. Acta Bioquímica Latino Americana, [S.1.], v. 38, n. 1, p. 39-46, 2004.

SCHECTMAN, G.; BYRD, J. C.; GRUCHOW, H. W. The influence of smoking on vitamin C status in adults. American Journal of Public Health, [S.l.], v. 79, n. 2, p. $158-162,1989$. 
SKYLER, J. S. Effects of glycemic control on diabetes complications and on the prevention of diabetes. Clinical Diabetes, [S.1.], v. 22, n. 4, p. 162-166, 2004.

SMIRNOFF, N. Ascorbic acid: metabolism and functions of a multi-facetted molecule. Current Opinion in Plant Biology, [S.1.], v. 3, n. 3, p. 229-235, 2000.

VIEIRA, J. G. H. Avaliação dos potenciais problemas pré-analíticos e metodológicos em dosagens hormonais. Arquivo Brasileiro de Endocrinologia e Metabologia, [S.1.], v. 46, n. 1, p. 9-15, 2002.

WILL, S.; ROGLIC, G.; GREEN, A. et al. Global prevalence of diabetes. Diabetes Care, [S.1.], v. 27, n. 10, p.2568-2569, 2004.

WHO. Diabetes programme. Disponível em: http://www.who.int/diabetes/ facts/ en/index.html. Acesso em: 25 ago. 2008. 